\title{
Single intra-articular injection of high molecular weight hyaluronic acid for hip osteoarthritis
}

\author{
Fabrizio Rivera ${ }^{1}$
}

Received: 10 August 2015/Accepted: 16 September 2015/Published online: 8 October 2015

(c) The Author(s) 2015. This article is published with open access at Springerlink.com

\begin{abstract}
Background Intra-articular (IA) injection of hyaluronic acid (HA) into the hip joint appears to be safe and well tolerated but only a small number of randomized clinical trials in humans has been published. The objective of this prospective study was to evaluate the efficacy and safety of a single IA injection of high-molecular-weight $(2800 \mathrm{kDa})$ HA (Coxarthrum) for hip osteoarthritis.

Materials and methods All patients received a single IA administration of $2.5 \%$ sodium hyaluronate $(75 \mathrm{mg} / 3 \mathrm{~mL})$ of high molecular weight. Fluoroscopy requires an iodized contrast medium (iopamidol, $1 \mathrm{ml}$ ) which highlights the capsule before administering HA. Patients were evaluated before IA injection (T0), after 3 months, after 6 months and after 1 year from injection. Results were evaluated by the Brief Pain Inventory (BPI II), Harris Hip Score and a visual analog scale of pain (pain VAS). All treated patients were considered for statistical analysis.

Results Two hundred seven patients were included at T0. The mean age was 67 years (range 46-81). Regarding BPI severity score, changes in pain between T0 and the three following visits were statistically highly significant $(p<0.001)$. Changes in pain score compared to the previous visit were statistically significant for the worst pain in the second quarter post-intervention $(p=0.037)$ and for mean pain in the second semester post-intervention ( $p=0.043)$ The evolution of the Harris Hip Score was statistically highly significant $(p<0.001)$ between T0 and the following visits $(\mathrm{T} 0+3$ months, T0 +6 months and
\end{abstract}

\section{Fabrizio Rivera} rivgio@libero.it

1 Department of Orthopedic Trauma, SS Annunziata Hospital, Via Ospedali 14, 12038 Savigliano (CN), Italy
T0 +12 months); after a significant change between T0 and $\mathrm{T} 0+3$ months, the score remained stable. The evolution of the pain VAS showed a statistically highly significant improvement $(p<0.001)$ between T0 and T0 +3 months; thereafter it remained stable from the first quarter post-intervention. No serious adverse event was noted; 12 cases $(0.5 \%)$ of pain associated with transient synovitis are noteworthy.

Conclusion This study shows that a single IA injection of Coxarthrum is effective from the third month and that the results are stable or continue to improve up to 1 year. Level of evidence IV.

Keywords Hip - Viscosupplementation - Hyaluronic acid

\section{Introduction}

Osteoarthritis has a very high prevalence globally. It is a source of pain and deterioration of joint function, with important socioeconomic consequences. The related pain is poorly evaluated by doctors, who underestimate its intensity when the pain is reported by the patient as being high, and overestimate it when it is reported as being weak [1]. The incidence of hip arthritis is increasing with age and is estimated at between 47.3 (95\% confidence interval [CI] 27.8-66.8) [1] and 88/100 000 patient-years (95\% CI 65-101) [2]. Hip pain is reported by $19.2 \%$ (95\% CI 17.9-20.6) of people aged 65 years and older. Less than half $(48 \%$ ) of the symptomatic respondents had unilateral problems affecting one hip or knee joint only [1].

Optimal management of osteoarthritis requires a combination of non-pharmacological and pharmacological modalities. Among the latter are injections of intra-articular (IA) hyaluronic acid (HA), first isolated in 1934 by Karl 
Meyer in the vitreous humor; the first human clinical use of IA HA in the treatment of knee arthritis was made in 1975, and the first trials date back to 1980 [1]. HA is a polysaccharide macromolecule, a glycosaminoglycan of high molecular weight (MW) composed of repetitions of disaccharides of glucuronic acid and $\mathrm{N}$-acetylglucosamine; it is a constituent of synovial fluid in normal and osteoarthritic joints and is synthesized by chondrocytes and synoviocytes [2]. HA has complex biological properties that could explain its analgesic effects (anti-inflammatory by inhibiting the formation and release of prostaglandin, immunomodulatory in situ), irrespective of its mechanical action on the joint fluid. The concentration of HA in an arthritic joint has been found to decrease to 50-33\% of normal levels, and includes a reduction in molecular size. Molecular interaction has also been observed, with a consequent decrease in elasticity and viscosity of the synovial fluid [3].

HA may be useful in patients with knee or hip osteoarthritis. The symptomatic benefit is delayed in comparison with that of intra-articular injections of corticosteroids, but it is prolonged. The IA injections of HA are widely used and recommended in existing guidelines as a useful therapeutic modality to treat patients with knee osteoarthritis; there is less experimental evidence of efficacy for hip arthritis than for knee arthritis [4].

IA injection of HA into the hip joint appears to be safe and well tolerated [5] but only a small number of randomized clinical trials in humans has been published [6-9].

Data from a meta-analysis in knee arthritis suggested that the heterogeneity between trials might be due to the higher MW products having greater efficacy. Indeed, HA preparations may broadly be classified according to their MW and formulation type: solutions of low MW (500-1200 kDa), solutions of high MW (6000 kDa), crosslinked HA and solutions of non-animal stabilized HA (NASHA) [10-12].

As a consequence, the objective of this prospective study was to evaluate the efficacy and safety of IA injection of a single dose of high MW (2800 kDa) HA (75 mg/ $3 \mathrm{~mL}$ ) (Coxarthrum, LCA Pharmaceutical, Chartres, France) for hip osteoarthritis.

\section{Materials and methods}

The study protocol was approved according to the modalities planned by Ethical Committee. We conducted a single-center, prospective, unblinded study. After baseline (T0), patients were to be reviewed at 3, 6 and 12 months. Inclusion criteria were age more than 40 years, mono- or bilateral hip arthritis with X-ray proof of at least partially preserved joint space (Kellgren-Lawrence stage 2-3 [10]), good or full joint mobility, and hip disease persisting for at least 3 months. Patients were excluded from the study where they had severe arthritis for which it was no longer possible to recognize radiographic joint space (KellgrenLawrence stage 4), had inflammatory, autoimmune and septic disease (rheumatoid arthritis, connective tissue disease, osteomyelitis), or had surgical indication for hip arthroplasty. All patients received a single injection of a single administration of $2.5 \%$ sodium hyaluronate $(75 \mathrm{mg} /$ $3 \mathrm{~mL}$ ) of high MW (2800 kDa) (Coxarthrum). This is a sterile, viscoelastic, transparent, homogeneous preparation composed of purified HA, without any avian protein; it is not cross-linked by a chemical agent, which limits as much as possible the risks of allergic and cytotoxic reactions. Injections were performed by fluoroscopic guidance. Fluoroscopy requires an iodized contrast medium (iopamidol, $1 \mathrm{ml}$ ) which highlights the capsule before administering HA. Patients were evaluated before IA injection (T0), after 3 months, after 6 months and after 1 year from injection. The first endpoint was the score on the Modified Brief Pain Inventory (BPI II) comprising (1) a score of pain severity (BPI severity score) rated between zero and 10 and measuring the pain which the subjects felt before the present visit (the worst pain, the lightest pain, the mean pain) and the pain now, that is to say the pain felt during the visit; (2) an impact score (BPI interference score) rated between zero and 10, describing disturbances of social life (work, sleep and mood); (3) an overall impact score adding the previous score and four other items (activities in general, ability to walk, relationships with others, the enjoyment of life). Another criterion of evaluation was the Harris Hip Score whose range is from zero to 100 with points distributed within four areas: "pain" domain, maximum 44 points; "function" domain, maximum 47 points; "range of motion" domain, maximum 5 points; "no deformity" domain, maximum 4 points. Finally, a visual analog scale (VAS) of pain (pain VAS), scored from zero to 10, also allowed judging the effectiveness of IA HA.

All treated patients were considered for statistical analysis, which was performed in SAS $^{\circledR}$ software (version 9.2). At each study time $(\mathrm{T} 0, \mathrm{~T} 0+3$ months, $\mathrm{T} 0+6$ months and T0 +12 months), mean, standard deviation and median endpoints were calculated. For the same endpoint, comparisons were made at different study times using Student's $t$ test for paired samples. Results were considered statistically significant for values of $p<0.05$.

\section{Results}

Two hundred seven patients were included at T0. One hundred twenty-six were women $(61 \%)$ and eighty-one were men (49\%). The mean age was 67 years (range 
Table 1 Number of patients completing the questionnaires at the various visits

\begin{tabular}{lllll}
\hline & \multicolumn{2}{l}{ No. of patients available at } & & \\
\cline { 2 - 5 } & T0 & T0 +3 months & T0 +6 months & 150 \\
BPI II questionnaire (severity and interference) & 207 & 207 & 12 months \\
Harris Hip Score & 207 & 207 & 128 & 121 \\
VAS of pain & 165 & 176 & 121 \\
\hline
\end{tabular}

Table 2 Evolution of patients' pain (BPI II severity score)

\begin{tabular}{lllll}
\hline \multicolumn{4}{l}{$l$} & \multicolumn{2}{l}{ Mean pain rating (out of 10) \pm SD } \\
\cline { 2 - 5 } & $\begin{array}{l}\text { Before and } \\
\text { at T0 }\end{array}$ & $\begin{array}{l}\text { Between T0 and } \\
\text { T0 }+3 \text { months }\end{array}$ & $\begin{array}{l}\text { Between T0 }+3 \text { months } \\
\text { and T0 }+6 \text { months }\end{array}$ & $\begin{array}{l}\text { Between T0 }+6 \text { months and } \\
\text { T0 }+12 \text { months }\end{array}$ \\
\hline Worst pain & $6.03(1.51)$ & $4.78(1.95)^{*}$ & $4.90(2.16)^{*}, \dagger$ & $4.80(2.00)^{*}$ \\
Slightest pain & $3.80(1.92)$ & $2.91(1.68)^{*}$ & $2.52(1.61)^{*}$ & $2.42(1.43)^{*}$ \\
Mean pain & $4.93(1.49)$ & $3.78(1.64)^{*}$ & $3.42(1.68)^{*}$ & $3.22(1.57)^{*} \dagger$ \\
Pain during visit & $4.07(2.04)$ & $3.00(1.94)^{*}$ & $2.73(1.98)^{*}$ & $2.55(1.63)^{*}$ \\
\hline
\end{tabular}

* Statistically highly significant $(p<0.001)$ compared with T0

$\dagger$ Statistically significant $(p<0.05)$ compared with the previous visit

46-81). Mean body mass index $\left(\mathrm{kg} / \mathrm{m}^{2}\right)$ was 22.8 (range 18.8-29.9). Radiological evaluation of osteoarthritis showed a Kellgren-Lawrence stage 2 in 83 (40.1\%) patients and a Kellgren-Lawrence stage 3 in 124 (59.9\%) patients. The number of included patients who completed the questionnaires in the various planned visits gradually decreased over time; however, data from three-quarters of patients were still available after 6 months, and data from over half the patients after 1 year. The data of pain VAS were less available than those of the BPI II questionnaires and the Harris Hip Score (Table 1).

Regarding the BPI severity score, changes in pain between $\mathrm{T} 0$ and the three following visits were statistically highly significant $(p<0.001)$. Changes in pain score compared to the previous visit were statistically significant for the worst pain in the second quarter post-intervention $(p=0.037)$ and for mean pain in the second semester postintervention $(p=0.043)$ (Table 2). Changes in pain severity (BPI severity score) are shown in Fig. 1. Note the parallelism of the curves, although the intensity of the worst pain is virtually unchanged from $\mathrm{T} 0+3$ months onwards.

The evolution of the BPI interference score, describing disturbances of social life, measured between $\mathrm{T} 0$ and the three following visits, was statistically highly significant $(p<0.001)$ for the three items describing disturbances of social life (work, sleep and mood). The evolution of the BPI interference score measured against the previous visit was also highly significant $(p<0.001)$ from the second quarter post-intervention for sleep and for the second

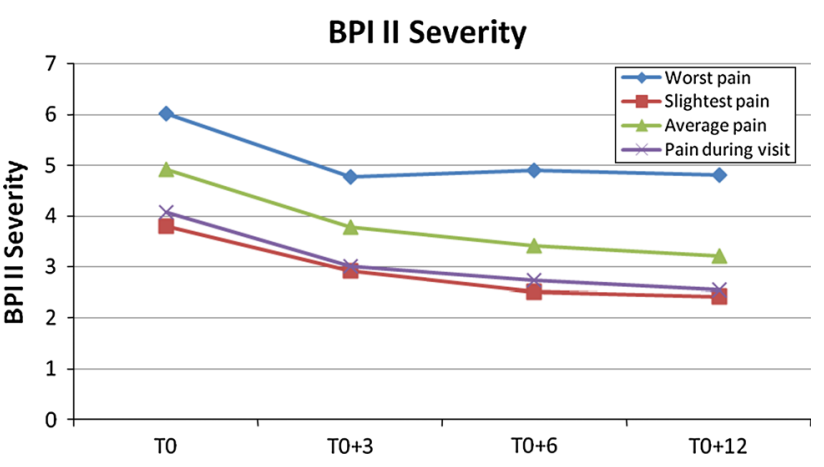

Fig. 1 Evolution of BPI Severity Score during follow-up

semester post-intervention for mood. It was significant $(p<0.05)$ concerning professional activities for the second semester post-intervention (Table 3 ).

The evolution of the BPI interference overall score between $\mathrm{T} 0$ and the three following visits was statistically highly significant $(p<0.001)$. The evolution of the BPI interference overall score measured against the previous visit was statistically significant in the second quarter postintervention $(p<0.01)$ and statistically highly significant during the second semester post-intervention $(p<0.001)$ (Table 4).

The evolution of the Harris Hip Score was statistically highly significant $(p<0.001)$ between T0 and the following visits ( $\mathrm{T} 0+3$ months, $\mathrm{T} 0+6$ months and $\mathrm{T} 0+12$ months); after a significant change between $\mathrm{T} 0$ and T0 +3 months, the score remained stable (Fig. 2). 
Table 3 Evolution of the BPI interference score describing disturbances of social life

\begin{tabular}{lllll}
\hline & \multicolumn{2}{l}{ Mean rating (out of 10$) \pm \mathrm{SD}$} \\
\cline { 2 - 5 } & $\begin{array}{l}\text { Before and } \\
\text { at T0 }\end{array}$ & $\begin{array}{l}\text { Between T0 and } \\
\text { T0 }+3 \text { months }\end{array}$ & $\begin{array}{l}\text { Between T0 }+3 \text { months } \\
\text { and T0 }+6 \text { months }\end{array}$ & $\begin{array}{l}\text { Between T0 }+6 \text { months } \\
\text { and T0 }+12 \text { months }\end{array}$ \\
\hline Professional activities & $4.44(2.15)$ & $3.42(1.94)^{*}$ & $3.26(2.45)^{*}$ & $2.59(1.97)^{*, \dagger}$ \\
Sleep & $3.80(2.23)$ & $2.59(1.76)^{*}$ & $2.01(1.78)^{*, \sqrt{ }}$ & $1.31(1.17)^{*, \sqrt{ }}$ \\
Mood & $4.11(2.18)$ & $3.14(2.12)^{*}$ & $2.79(2.45)^{*}$ & $1.83(1.61)^{*, \sqrt{ }}$ \\
\hline
\end{tabular}

* Statistically highly significant $(p<0.001)$ compared with T0

$\dagger$ Statistically significant $(p<0.05)$ compared with previous visit

$\checkmark$ Statistically highly significant $(p<0.001)$ compared with previous time

Table 4 Evolution of the BPI interference overall score at the different visits

\begin{tabular}{|c|c|c|c|c|}
\hline & $\begin{array}{l}\text { Before and } \\
\text { at T0 }\end{array}$ & $\begin{array}{l}\text { Between } \mathrm{T} 0 \text { and } \\
\mathrm{T} 0+3 \text { months }\end{array}$ & $\begin{array}{l}\text { Between T0 }+3 \text { months } \\
\text { and T0 }+6 \text { months }\end{array}$ & $\begin{array}{l}\text { Between T0 }+6 \text { months } \\
\text { and T0 }+12 \text { months }\end{array}$ \\
\hline Mean $( \pm \mathrm{SD})$ & $30.40(13.65)$ & $22.81(11.92)^{*}$ & $19.83(13.72)^{* \dagger \dagger}$ & $14.17(9.78)^{*, \sqrt{ }}$ \\
\hline Median & 30 & 20 & 20.5 & 10 \\
\hline
\end{tabular}

* Statistically highly significant $(p<0.001)$ compared with T0

+ Statistically significant $(p<0.01)$ compared with previous time

$\checkmark$ Statistically highly significant $(p<0.001)$ compared with previous visit

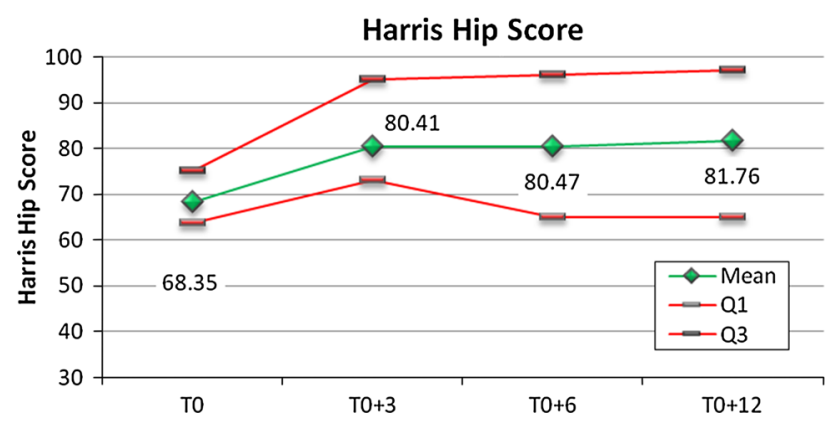

Fig. 2 Evolution of Harris Hip Score during follow-up

As for the evolution of the Harris Hip Score, the evolution of the pain VAS showed a statistically highly significant improvement $(p<0.001)$ between T0 and $\mathrm{T} 0+3$ months; thereafter it remained stable from the first quarter post-intervention.

No serious adverse event was noted; 12 cases $(0.5 \%)$ of pain associated with transient synovitis (during $24 \mathrm{~h}$ ) are noteworthy.

\section{Discussion}

To evaluate the efficacy and safety of a single IA of HA (75 mg/3 mL) of high MW (2800 kDa) (Coxarthrum) for hip osteoarthritis pain management, we included in our study two hundred seven patients. In this unblinded prospective study, changes in all outcome measures were significantly in favor of a single IA injection, whether it was the BPI severity score, the BPI interference score, the Harris Hip Score or the pain VAS. This trend was very clear from $\mathrm{T} 0+3$ months; then the results remained stable or continued to improve on all these criteria.

Only a small number of scientific papers containing statistically significant results about hip IA injection of HA are available in the literature despite the hip being the second most common site of arthritis.

Conrozier and colleagues [11] retrospectively evaluated a group of 56 patients with severe or moderate hip osteoarthritis after one or two IA administrations of high MW HA. At 90 days follow-up, $58.9 \%$ of the patients reported a benefit of the infiltration treatment.

A prospective double-blind study compared the effect of high MW and low MW HA, together with a placebo. In this study 59 patients were evaluated at time intervals of 1, 3 and 6 months after the first infiltration. Similarly to our study, improvement of scores was noted at 1 month and remained significant up to 6 months in both groups compared to the placebo group $(p<0.001)$. No significant differences were observed between the results obtained in the two study groups treated with the different HA molecules [12].

Berg and Olsson [13] studied a group of 31 patients with hip osteoarthritis at 2 weeks and 3 months follow-up after a single administration of non-animal, stabilized HA 
(NASHA). Three months after administration, there was a statistically significant $68 \%$ improvement in symptoms $(p<0.007)$.

Colen and colleagues [5] evaluated the efficacy of hip viscosupplementation by analysing the results of 16 trials with a total of 509 patients, with evidence levels varying from I to IV, and using various types of preparations. Notwithstanding the relatively low level of evidence in the trials, the authors concluded that viscosupplementation may be an alternative therapy for treating coxarthrosis. Intra-articular infiltration has proved to be safe and welltolerated therapy. However, the authors state the need for trials on a larger number of people in order to avoid having to consider HA infiltration in the hip as an extremely selective choice that depends on the experience of the operator. The same group of authors [14] reported that $51 \%$ of the patients had not undergone surgery 3 years after viscosupplementation, after evaluation of a group of 120 patients who were candidates for surgical treatment with a total hip arthroplasty.

To overcome the problem of selectivity and operatordependent approach to hip viscosupplementation, a clear identification of whether or not the patient is suitable for HA infiltration treatment in the hip is mandatory. Although studies of variability in the efficacy of HA infiltration therapy in the hip compared to the gravity of the hip arthritis have not yet been carried out, it can reasonably be assumed, as reported by knee viscosupplementation studies, that the possibilities of efficacy and duration of the beneficial effects of the treatment are inversely proportional to the gravity of the disease [15]. For this reason selection criteria for the candidate patient are vital to obtain pain relief in cases of hip arthritis. These selection criteria consist of hip pain for at least 3 weeks, X-ray proof of at least partially-preserved joint space, and good or full joint mobility. Hip viscosupplementation can be used as an alternative to or in combination with drugs for pain control. This type of approach to viscosupplementation therapy does not correspond to the inclusion criteria reported in Van den Bekerom and colleagues' study [14]. Considering hyaluronic acid as a pain therapy, using its beneficial effects on cartilage due to both the pharmacological and the physical properties of the molecule [16-18], then the use of injection in cases of low or medium degrees of hip arthritis is mandatory. For this reason, patient candidates for hip arthroplasty were excluded for our study.

Recently, to clarify some aspects of viscosupplementation treatment, a review of the literature confirmed that IA HA is an effective treatment for mild to moderate osteoarthritis but it is not an alternative to surgery in advanced cartilage degeneration [19].

Fluoroscopic guidance is one of the possible radiological guidances when performing IA hip injection. Due to the narrow IA space, performing a "blind" hip IA injection is not recommended [20]. Ultrasound guidance does not need contrast media and can also be repeated without causing problems of radiation load for the patient or operator, but exposure to radiation during fluoroscopy is minimal and there is no difference in the speed of IA injection between the two techniques when performed by experts. The choice between ultrasound or fluoroscopy is based on the experience of the operator in using both methods [20]. However, when IA injection is performed under fluoroscopy, the amount of radiopaque contrast agent must be as low as possible to avoid viscosupplement dilution [19].

In our experience, we observed 12 cases of pain associated with transient synovitis after IA injection. As reported in the literature [21-24], transient synovitis correlated with the reaction to a foreign body is a minor complication with an incidence of between 5 and $10 \%$. This adverse reaction normally resolves in $24-48 \mathrm{~h}$ following infiltration. without long-term clinical effects.

Further studies are needed on unresolved hip viscosupplementation issues including cost-effectiveness of therapy, relation between molecular weight and effectiveness, and how to best incorporate viscosupplementation into an arthritis therapy algorithm. Our experience proved the efficacy of IA HA injection for hip arthritis treatment.

A single dose of $\mathrm{HA}(75 \mathrm{mg} / 3 \mathrm{~mL})$ of high $\mathrm{MW}$ $(2800 \mathrm{kDa})$ is proving to be safe and effective for pain control in patients with hip arthritis (Kellgren-Lawrence stages 2 and 3) before indications for hip arthroplasty. Viscosupplementation is effective from the third month and the results are stable or continue to improve up to 1 year.

\section{Compliance with ethical standards}

Conflict of interest This research received no specific grant from any funding agency in the public, commercial, or not-for-profit sectors.

Ethical standards This study was authorized by the local ethical committee and was performed in accordance with the ethical standards of the 1964 Declaration of Helsinki as revised in 2000. The ethical committee waived the need for informed consent since the rights and interests of the patients would not be violated and their privacy and anonymity would be assured by this study design.

Open Access This article is distributed under the terms of the Creative Commons Attribution 4.0 International License (http://creative commons.org/licenses/by/4.0/), which permits unrestricted use, distribution, and reproduction in any medium, provided you give appropriate credit to the original author(s) and the source, provide a link to the Creative Commons license, and indicate if changes were made.

\section{References}

1. Tait RC, Chibnall JT (1997) Physician judgments of chronic pain patients. Soc Sci Med 45:1199-1205 
2. Wilson MG, Michet CJ Jr, Ilstrup DM, Melton LJ 3rd (1990) Idiopathic symptomatic osteoarthritis of the hip and knee: a population-based incidence study. Mayo Clin Proc 65(9):1214-1221

3. Balazs EA, Denlinger JL (1993) Viscosupplementation: a new concept in the treatment of osteoarthritis. J Rheumatol 39:3-9

4. Zhang W, Moskowitz RW, Nuki G, Abramson S, Altman RD, Arden N, Bierma-Zeinstra S, Brandt KD, Croft P, Doherty M, Dougados M, Hochberg M, Hunter DJ, Kwoh K, Lohmander LS, Tugwell P (2008) OARSI recommendations for the management of hip and knee osteoarthritis, part II: OARSI evidence-based, expert consensus guidelines. Osteoarthritis Cartilage 2:137-162

5. Van den Bekerom MP, Lamme B, Sermon A, Mulier M (2008) What is the evidence for viscosupplementation in the treatment of patients with hip osteoarthritis? Systematic review of the literature. Arch Orthop Trauma Surg 128:815-823

6. Colen S, van den Bekerom MP, Bellemans J, Mulier M (2010) Comparison of intra-articular injections of hyaluronic acid and corticosteroid in the treatment of osteoarthritis of the hip in comparison with intra-articular injections of bupivacaine. Design of a prospective, randomized, controlled study with blinding of the patients and outcome assessors. BMC Musculoskelet Disord 16(11):264-269

7. Atchia I, Kane D, Reed MR, Isaacs JD, Birrell F (2011) Efficacy of a single ultrasound-guided injection for the treatment of hip osteoarthritis. Ann Rheum Dis 70(1):110-116

8. Migliore A, Massafra U, Bizzi E, Vacca F, Martin-Martin S, Granata M, Alimonti A, Tormenta S (2009) Comparative, double-blind, controlled study of intra-articular hyaluronic acid (Hyalubrix) injections versus local anesthetic in osteoarthritis of the hip. Arthritis Res 11(6):183-186

9. Richette $\mathrm{P}$, Ravaud P, Conrozier T, Euller-Ziegler L, Mazières B, Maugars Y, Mulleman D, Clerson P, Chevalier X (2009) Effect of hyaluronic acid in symptomatic hip osteoarthritis: a multicenter, randomized, placebo-controlled trial. Arthritis Rheum 60(3):824-830

10. Ahlbäck S (1968) Osteoarthrosis of the knee: a radiographic investigation. Acta Radiol Stockholm Suppl 277:70-72

11. Conrozier T, Bertin P, Bailleul F, Mathieu P, Charlot J, Vignon E, Treves R, Chevalier X (2006) Clinical response to intra-articular injections of hylan G-F 20 in symptomatic hip osteoarthritis: the OMERACT-OARSI criteria applied to the results of a pilot study. Joint Bone Spine 73(6):705-709

12. Kotevoglu N, Lyibozkurt PC, Hiz O, Toktas H, Kuran B (2006) A prospective randomised controlled clinical trial comparing the efficacy of different molecular weight hyaluronan solutions in the treatment of knee osteoarthritis. Rheumatol Int 26:325-330

13. Berg P, Olsson U (2004) Intra-articular injection of non-animal stabilised hyaluronic acid (NASHA) for osteoarthritis of the hip: a pilot study. Clin Exp Rheumatol 2(3):300-306

14. Van den Bekerom MP, Rys B, Mulier M (2008) Viscosupplementation in the hip: evaluation of hyaluronic acid formulations. Arch Orthop Trauma Surg 18(3):275-280

15. Evanich DJ, Evanich CJ, Wright MB, Rydlewicz JA (2001) Efficacy of intrarticular hyaluronic acid injections in knee osteoarthritis. Clin Orthop 390:173-181

16. Vitanzo PC Jr, Sennett BJ (2006) Hyaluronans: is clinical effectiveness dependent on molecular weight? Am J Orthop 35(9):421-428

17. Lindholm A, Ronéus B, Lindblad G, Jones B (1996) Hyaluronan turnover in the synovial fluid in metacarpophalangeal-and middle carpal joints in standardbred horses. Acta Vet Scand 37(2):147-151

18. Lùrati $\mathrm{A}$, Laria $\mathrm{A}$, Mazzocchi $\mathrm{D}$, Re KA, Marrazza M, Scarpellini M (2015) Effects of hyaluronic acid (HA) viscosupplementation on peripheral $\mathrm{Th}$ cells in knee and hip osteoarthritis. Osteoarthritis Cartilage 23(1):88-93

19. Henrotin Y, Raman R, Richette P, Bard H, Jerosch J, Conrozier T, Chevalier X, Migliore A (2015) Consensus statement on viscosupplementation with hyaluronic acid for the management of osteoarthritis. Semin Arthritis Rheum 30 2015.04.011

20. Rivera F (2014) Can viscosupplementation be used in the hip? An Italian perspective. Orthopedics 37(1):48-55

21. Goomer RS, Leslie K, Maris T, Amie ID (2005) Native hyaluronan produces less hypersensitivity than cross-linked hyaluronan. Clin Orthop 434:239-245

22. Morton AH, Shannon P (2003) Increased frequency of acute local reaction to intra-articular Hylan G-F 20 (Synvisc) in patients receiving more than one course of treatment. J Bone Joint Surg A 85:2050-2051

23. Goldberg VM, Coutts RD (2004) Pseudoseptic reactions to hylan viscosupplementation: diagnosis and treatment. Clin Orthop 419:130-137

24. Juni P, Reichenbach S, Trelle S, for the Swiss Viscosupplementation Trial Group et al (2007) Efficacy and safety of intraarticular hylan or hyaluronic acids for osteoarthritis of the knee: a randomized controlled trial. Arthritis Rheum 56:3610-3619 